\title{
Occupational injuries in Italy: risk factors and long term trend (1951-98)
}

\author{
B Fabiano, F Currò, R Pastorino
}

\begin{abstract}
Objectives-Trends in the rates of total injuries and fatal accidents in the different sectors of Italian industries were explored during the period 1951-98. Causes and dynamics of injury were also studied for setting priorities for improving safety standards.

Methods-Data on occupational injuries from the National Organisation for Labour Injury Insurance were combined with data from the State Statistics Institute to highlight the interaction between the injury frequency index trend and the production cycle-that is, the evolution of industrial production throughout the years. Multiple regression with log transformed rates was adopted to model the trends of occupational fatalities for each industrial group.
\end{abstract}

Results-The ratios between the linked indices of injury frequency and industrial production showed a good correlation over the whole period. A general decline in injuries was found across all sectors, with values ranging from $\mathbf{7 9 . 8 6 \%}$ in the energy group to $23.32 \%$ in the textile group. In analysing fatalities, the trend seemed to be more clearly decreasing than the trend of total injuries, including temporary and permanent disabilities; the fatalities showed an exponential decrease according to multiple regression, with an annual decline equal to $4.42 \%$.

Conclusions-The overall probability of industrial fatal accidents in Italy tended to decrease exponentially by year. The most effective actions in preventing injuries were directed towards fatal accidents. By analysing the rates of fatal accident in the different sectors, appropriate targets and priorities for increased strategies to prevent injuries can be suggested. The analysis of the dynamics and the material causes of injuries showed that still more consideration should be given to human and organisational factors.

(Occup Environ Med 2001;58:330-338)

Chemical and Process Engineering Department "G B

Bonino", University of Genoa, Via Opera Pia 15,16145 Genoa, Italy

B Fabiano

F Currò

R Pastorino

Correspondence to:

Dr B Fabiano

email: brown@unige.it

Accepted 8 December 2000

Keywords: labour injuries; severity; regression model

This paper aims to point out the main factors affecting the risk in industrial activities, considering in particular data on both occupational fatal and non-fatal injuries in Italy over a long period, for the different sectors of industrial activities.

Four main factors can be identified as affecting productivity ${ }^{1}$ : socioeconomic factors; typical technologies used; environmental conditions; and labour force characteristics (especially age and experience). ${ }^{2}{ }^{3}$ Among them, the socioeconomic factors may be considered the most important, in that they exert a considerable influence on the injury frequency, especially if considered over a long period. ${ }^{4}$ The economic trend is closely connected to production dynamics, involving technologies, environment, work organisation, and workforce. The socioeconomic factors to which recent studies were referred are the quality of labour relations $s^{5}$; the economic climate ${ }^{2}$; the unemployment rate; and occupational legislation. ${ }^{6}$ In particular, the influence of the production pressure on the injury rate is presented in this paper, by correlating the injury frequency indices with the industrial production indices. The high degree of correlation between the two indices shows that the factors influencing human safety in industrial activities do not depend on technological development, ${ }^{7}$ and that technological changes do not have a universally preventive effect on injuries and accidents. In some workplaces advances in technology have been associated with higher injury frequency; in others with risk transfer; in still others with the appearance of new hazards. ${ }^{8}$

An in depth analysis of the type and characteristics of injuries and of the injuring agent or cause allows evaluation of the influence of technological evolution on these aspects of occurrence of industrial injury.

\section{Methods}

The occupational fatal and non-fatal injury data were obtained from the National Organisation for the Labour Injury Insurance (INAIL). ${ }^{9}$ The frequency indices show the incidence of accidents of the workers exposed to risk, and are defined as follows, respectively for total accidents and fatalities:

$$
\begin{aligned}
& F I=\frac{\text { Number of total accidents }}{\text { Number of working hours }} 10^{6} \\
& F A F R=\frac{\text { Number of fatalities }}{\text { Number of working hours }} 10^{8}
\end{aligned}
$$

Therefore index (1) is a measure of the rate of injuries per million of hours worked and index (2) is a measure of the rate of the fatal injuries per $10^{2}$ million hours worked.

As the reference variable-that is, working hours - can be calculated regularly and refers to risk at a particular time, the indices already mentioned can represent a proper instrument of evaluation of the dynamics and evolution of the injuries. The limiting factors in the analyzed 


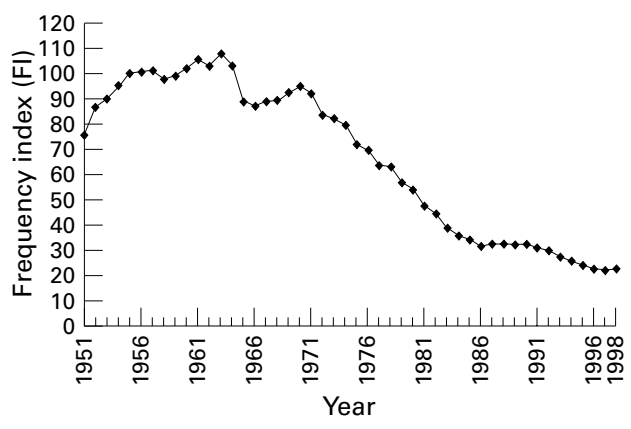

Figure 1 Overall accident frequency index (FI) over the period 1951-98.

data are that accidents involving absence from work for less than 3 days, which can occur more often than those causing longer absence, are not considered. Moreover, injuries in which the employment is not regularly signed and registered (moonlighting) are not taken into account. According to the CENSIS (Centre for Social Studies and Policies, Italy) report, ${ }^{10}$ moonlighting employment throughout Italy corresponds to $17.8 \%$ of national regular employment, but in southern Italy, the percentage is as high as $31.3 \%$. Under these circumstances, we can expect the injury frequency index (FI) and fatal accident frequency rate (FAFR) to be underestimates, especially in those sectors with high FI and FAFR (construction), where manpower not regularly registered is characterised by a low degree of experience and specialisation (immigrants and young people). These limitations and possible criticisms of traditional injury statistics apply not only to the Italian situation, but worldwide. The problem of improving the organisational memory, and the need for a new look at the sort of injury data that are collected and analyzed ${ }^{11}$ are becoming more and more important.

To obtain a strong statistical correlation with the production cycle, industrial production data supplied by the National Statistic Institute (ISTAT) were adopted.

Starting from (1), the linked indices of the total injury frequency were defined as:

$C F I=\frac{F I_{i}}{F I_{i-1}} 100$

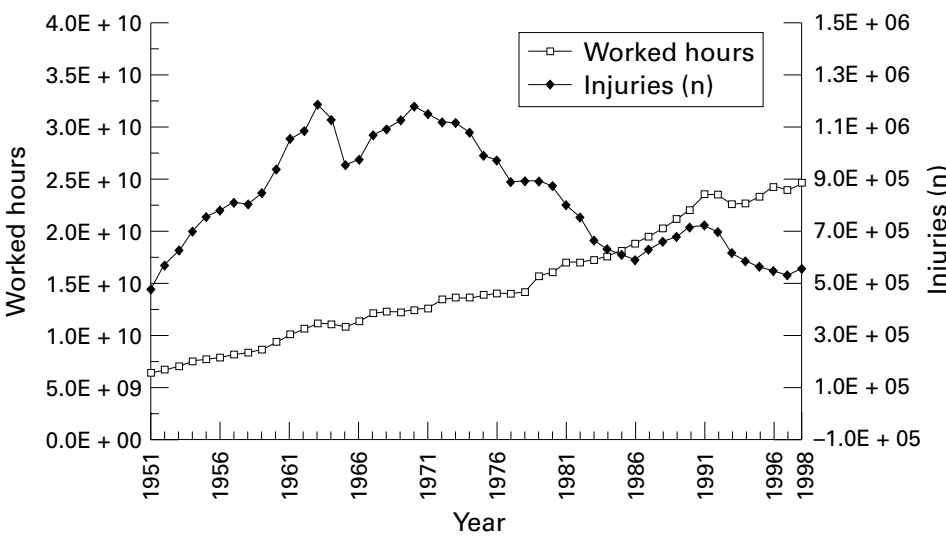

Figure 2 Worked hours and total injuries versus year, over the period 1951-80. (Values of hours worked and injuries are reported as powers so-for example, $5.0 E+09=5.0 \times 10^{9}$.) where FIi is the injury FI of the i-th year.

Similarly, the linked indices of the industrial production were calculated as:

$C P I=\frac{P I_{i}}{P I_{i-1}} 100$

where $\mathrm{PI}_{\mathrm{i}}$ is the industrial production index of the i-th year, according to ISTAT definition and statistical data. ${ }^{12}$

The occupational FAFR was modelled as an explicit function of the year, by adopting a multiple regression model with log transformed rates, as follows ${ }^{13}$ :

$\ln (F A F R)=a+b\left(\right.$ year $_{i}-$ year $\left._{0}\right)$

where year ${ }_{0}$ is the first year considered in the present analysis (1951).

The occupational FAFR for all industries was modelled also as an explicit function of the year and the production, by a linear model with a log link, as follows:

$$
\begin{aligned}
\ln (F A F R)= & a+b_{1}\left(\text { year }_{i}-\text { year }_{0}\right) \\
& +b_{2}\left(P I_{i}-P I_{0}\right)
\end{aligned}
$$

where $\mathrm{PI}_{0}$ is the production index corresponding to the first year considered in the present analysis (1951).

The percentage annual systematic change of the FAFR, AV, was calculated according to:

$A V=100(1-\exp ($ trend parameter $))$ :

where the trend parameter corresponds to the fitted value of $b$ for each category.

To measure the goodness of fit of the fatal injury regression lines for the different sectors, we considered the coefficient of determination, defined as the ratio of the explained variation to the total variation.

From equation (5):

$$
\begin{aligned}
\hat{Y}_{i} & =\ln F A F R_{i} \\
X_{i} & =\text { year }_{i}-\text { year }_{0} \\
\hat{Y}_{i} & =a+b X_{i}
\end{aligned}
$$

The total variation in $\mathrm{Y}$ can be partioned into two components, the unexplained variation and the explained variation, respectively as follows:

$$
\begin{aligned}
\sum_{i=1}^{N}\left(Y_{i}-\bar{Y}\right)^{2}= & \sum_{i=1}^{N}\left(Y_{i}-\hat{Y}_{i}\right)^{2} \\
& +\sum_{i=1}^{N}\left(\hat{Y}_{i}-\bar{Y}\right)^{2}
\end{aligned}
$$

where $Y_{i}$ is the measured value and $\bar{y}$ is the mean value of $Y_{i}$.

\section{Results}

INJURY TREND

As stated, the purpose of this paper is to offer perspectives on the factors influencing occupational risk in the different Italian industrial sectors. Figure 1 depicts the trend of the total FI, for all industrial sectors, in the years 1951-98. 


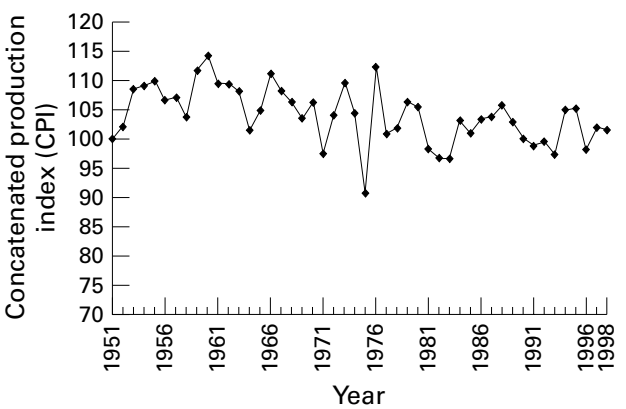

Figure 3 Concatenated industrial production index (CPI) covering the period 1951-98.

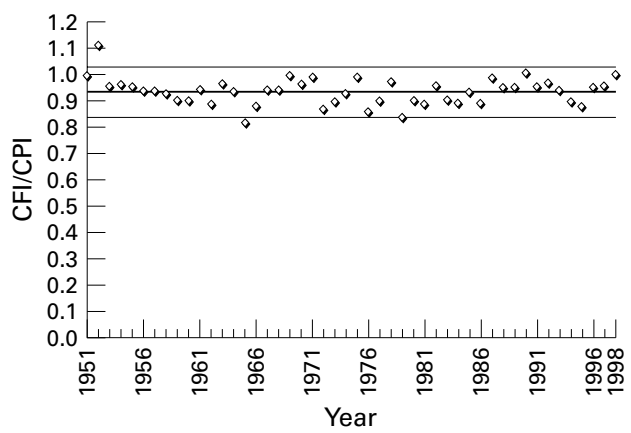

Figure 4 Accident frequency (CFI) and industrial production concatenated indices (CPI) ratio covering the period 1951-98.

The change of worked hours during the investigated period is highlighted in figure 2 , reporting, as well, total accident trend. It is worth noting that the trend was characterised by a major increase in industrial injuries in the years immediately after the second world war, with its highest peak in the year 1963 (FI=107.63; 1183091 injuries). The marked decrease in the year 1962 was correlated only to a change in the injury report duty for the food and agriculture sector. The trend was correlated with the postwar industrial rebuilding phase, starting the period of economic expansion and leading to the so called Italian economic boom. These years were characterised by a high percentage of plant use as well as by a consistent immigration of workers from southern Italy towards the industrialised northern Italy. Inadequate preparation for the use of new equipment and a change in the employment sector (mainly from agriculture to industry) characterise an immigrant workforce. The so called human factor plays a prominent part in frequency of injuries, where human errors are mainly due to lack of experience ${ }^{23}$ and poor instructions or training.

The mechanisation and partial automation represent challenges to the work capacity of older workers in particular, posing adaptation problems of various types. ${ }^{14}$ A key aspect is that, as reported by Asogwa, ${ }^{15}$ an adaptation period is required for workers to perform satisfactorily in new work jobs and a changed environment, but when the pressure of production was intensified (as in the years 1951-65) this training period was usually reduced or eliminated. Moreover, intensification of work and production in combination with an increase in

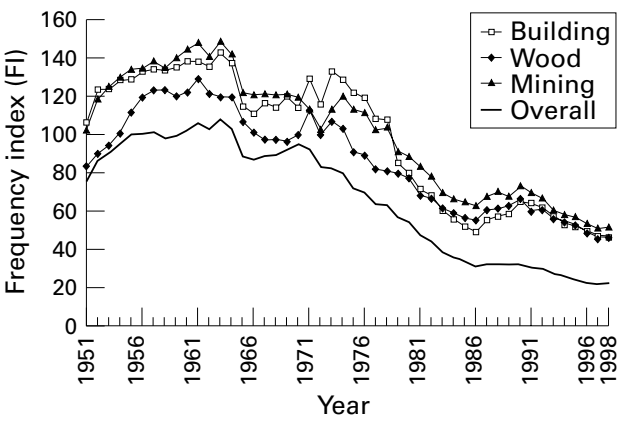

Figure 5 Accident FI in the building, mining, and wood sectors.

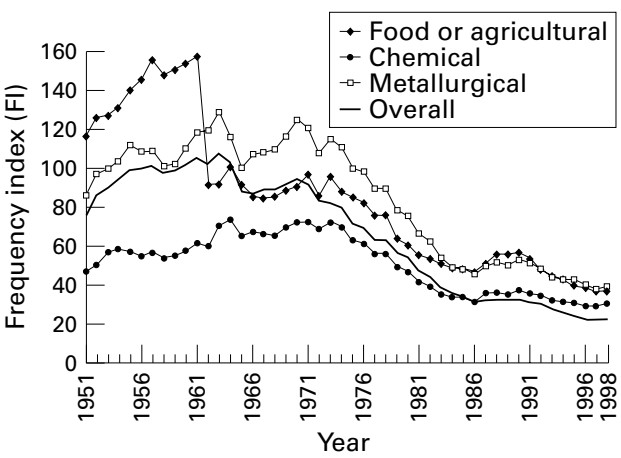

Figure 6 Accident FI in the food and agricultural, metallurgical, and chemical sectors.

overtime (characteristic of the period) constituted a set of interacting factors that increase risk of injury. ${ }^{6}$

From the year 1970 onwards, the FI declined, due to the continuous development of safety techniques, and the adoption of more legislative constraints that affected industrial health and safety.

When the whole period was considered, the trend of injuries did not seem to be monotonic; periods of falling frequency of injuries alternated with periods of upswing. A better evaluation of the dynamics of injuries can be obtained by analysis of the production cycle. ${ }^{4}$

The evolution of the Italian production cycle is reported in figure 3. Because the linked production index showed a cyclic trend, the rate of production increased and decreased from one year to another. A marked fall was evident in connection with events that influenced the economic cycle of the whole world-for example, the oil shock in 1975. This cyclic trend, characterised by periods of economic expansion followed by recession, affects the variations of the injury FI. A high degree of correlation between the FI and the economic cycle is highlighted in figure 4 , which shows the ratios between the linked indices both of the injury frequency FI and of the industrial production PI. The corresponding degree of correlation over a long period showed a $95 \%$ confidence interval $(95 \% \mathrm{CI})$ of 0.9234 to 0.9531 .

The effect of group of industry on injury rate is clearly shown in figures $4,5,6$, and 7 .

The occupations with the highest rates of accidents (building, mining, and wood) showed a similar trend among them, constantly above the mean of all industries, and with more marked evidence of the cyclic evolution (fig 5). 


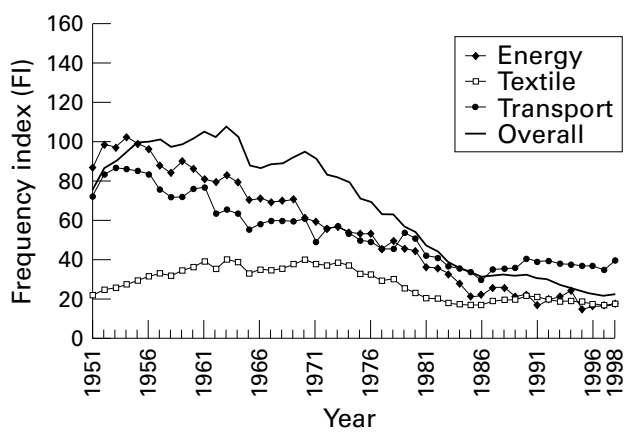

Figure 7 Accident FI in the textile, energy, and transport sectors.

This feature was partially due to the high interdependence of these sectors, particularly evident in the postwar years, when the plastic and new materials sector was not developed. In the years from 1990 onwards, in connection with the rediscovery of old construction materialsfor example, wood-in bioarchitecture, this common trend is particularly evident again. The metallurgical group (fig 6) shows high frequency indices for injuries, and this trend affects the global trend, because it comprises about $30 \%$ of the working hours in Italy. The chemical group was for many years (1951-63) characterised by a low frequency of injuries, but in subsequent years injuries showed an increasing trend that reached its peak in the year 1973. In recent years, a decline was found, although from 1986 onwards injuries were at a constant frequency, the Italian trend was above the global one. The food and agricultural sector is an obvious case to study in this analysis, with the fall in 1963 that has been mentioned already. It is worth noting that the increasing trend in the 1950s was closely connected to the introduction of mechanisation and partial automation in agriculture. The textile group (fig 7) always had above average injuries with a response that has not changed with time. Transport and energy were characterised by the severity of accidental injuries: permanent disability and fatalities. The transport group was constantly above the average trend.

A general decline in the frequency of the injuries was found across all industries, as in the analysis of the 5 year average FI values. A significant decline of the average value of the FI in the years 1949-53 versus 1994-8, over the nine industry groups considered, ranged from $79.86 \%$ in energy to $23.32 \%$ in textiles. From a comparative analysis of the different groups it is evident that the overall decreases in FI of the textile and chemical industries corresponded respectively to $48.13 \%$ and $54.90 \%$ of the peaks in the whole period, whereas the actual values were comparable with the ones in the 1950s. Transport industry showed a slow and continuous decrease in FI down to a constant value corresponding to $50.04 \%$ of the average value in the period of the postwar industrial rebuilding. Practically speaking, all the sectors approached minimum values of the FI, which can be regarded as a statistically reinforced reference for the minimum risk per man employed in the different industrial activities. Obviously, this is only a statistical consideration, and should not be regarded as an attempt to renounce the effort of reducing even the lowest injury frequency recorded. After the application of all possible technical and management factors to reduce risk and the integration of prevention (safety, health, and ergonomics) in the design process, several injuries still remained. These accidents were not related to the process itself and require a

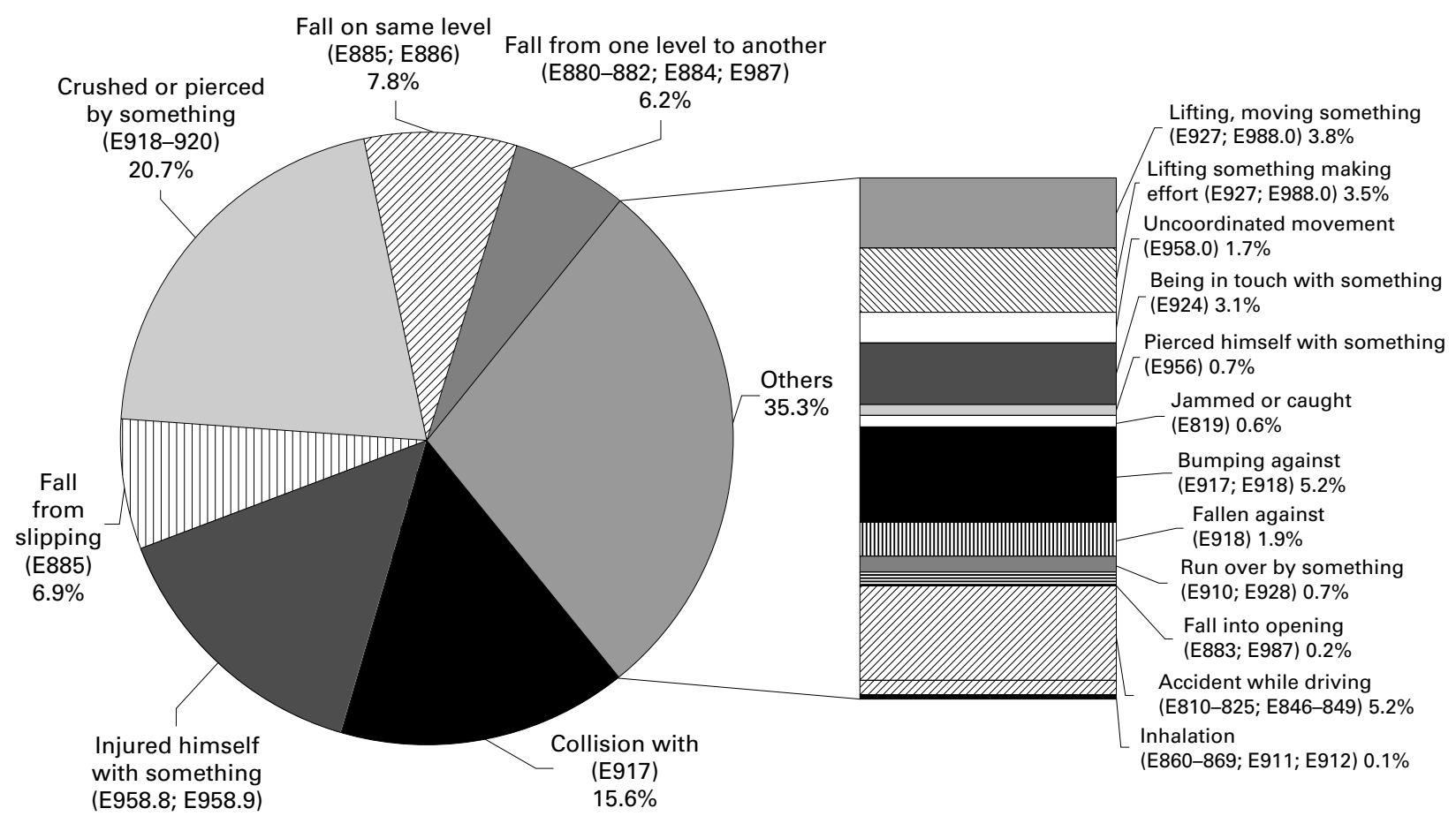

Lifting, moving something (E927; E988.0) 3.8\% Lifting something making effort (E927; E988.0) 3.5\% ed movement

Being in touch with something E924) $3.1 \%$

Pierced himself with something

E819) $0.6 \%$ E918) $5.2 \%$ (E910; E928) 0.7\% Accident while drivin halation with something $15.6 \%$

$$
14.4 \%
$$

Figure 8 Dynamics of total accident: average values in the period 1994-8. 




Figure 9 Dynamics of total accident: 5 year average values in the period 1994-8.

deeper analysis - that is, injury type, cause, and material agent) to show the important factors contributing to the risk.

\section{INJURY FACTORS}

In analysing the data of the dynamics of the injuries, related to the mean numbers of injuries in 1994-8 (fig 8) (injuries are related to $\mathrm{E}$ codes from the international classification of diseases (ICD), ${ }^{16}$ we found that about one third of injuries in the workplace resulted from falls (E880-888; 16.0\%) and collisions (E917; $15.6 \%)$. It is clear that direct simple intervention in work organisation and environment could affect the level of risk to operators: fixed courses, safety ranges, and installation of railings, handrails, and catwalks. Unfortunately, these interventions are often disregarded.

In our studies, accidents directly connected to work organisation and environment were the most important. This occurs not only in Europe and the United States, but also in the emerging markets. For example, over recent years, the Council of Labour Affairs in Taiwan noticed the seriousness of accidental falls and injuries, and strongly encouraged the use of relevant protection against falls-for example, helmets, safety nets, handrails, safety belts, and reins. ${ }^{17}$

A high number of injuries $(20.7 \%)$ involved the operators passively (crushed or pierced by something E918-920) and were caused by the lack of guards, safety devices, protective equipment, and clothing.

Another relevant cause of injuries was the use of tools (injured himself with something, E958.8, E958.9; 14.4\%). This factor indicates the necessity of adequate training of the operators; each operation should be conducted strictly in accordance with procedures and checklists.

The remaining $35.25 \%$ of injuries were caused by less important factors related to the process being performed.
By analysing the trend of the 5 year averages (fig 9) in the period 1974-98, we found a considerable constancy between falls, a decrease in passive events and imprudent movements, and an increase in injuries caused by improper use of tools, equipment, and facilities.

The aim of a correct and useful safety practice therefore should be to provide equipment and procedures able to minimise possible errors by operators, designs should avoid possible injuries in cases of operator error, and designs and safeguards should be able to prevent injury if an accident occurs. The analysis of injuries should assess whether such activities are improving safety: new ideas are required, developed over time, which would gradually be accepted by the workforce. ${ }^{18}$

The analysis of the material causes of injuries should provide useful data: figure 10 shows the average distribution of the material causes of accidents over the period 1994-8. Figure 11 shows the trend of the average from a 5 year base during the period 1974-98.

We found that considering the whole period, contrary to the injury dynamics, the percentage variation was not remarkable. Because of a more detailed description of the notification of injuries, some parts of industry showed increased injuries, E917, E918, E920, but the injuries connected with machines (E919) declined.

In the past 5 years, about half of the injuries were directly related to work organisation and environmental conditions (labour environment E880, E916-918, E928, 21.54\%, and material, substances, radiations E 860-869, E890-899, E923-926; 24.52\%).

The main conclusion of this analysis is that development of technology is not effective in reducing industrial injuries. The magnitude, type, and distribution of risks of injury after the implementation of a technological change may depend on intrinsic characteristics of a new technology, but may also be conditioned by other factors that moderate its main effect. ${ }^{19}$ Our 


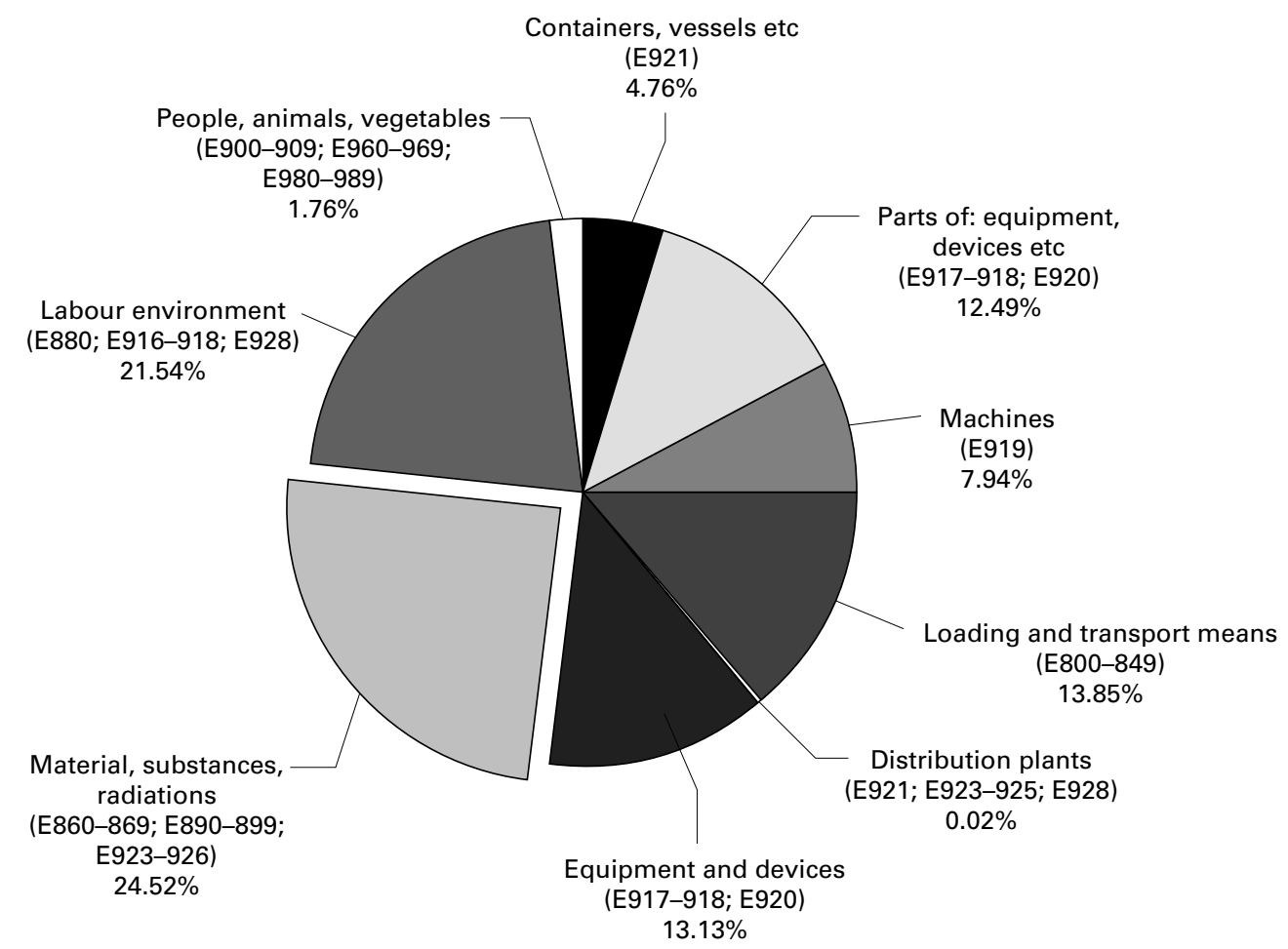

Figure 10 Total injuries from material causes: average values in the period 1994-8.

results on causes of injury should be considered in setting priorities to improve safety performance through improved equipment. However, such improvement must be accompanied by higher consideration of human factors - such as managerial and organisational systems.

SEVERITY OF INJURY

In occupational risks the extent of the damage incurred after an occupational accident or disease varied. ${ }^{20}$ Even if severity of an injury seems to be a multifaceted entity, for the purpose of this paper it seems preferable to adopt a simple classification of the consequences of an accident. Based on this simplified approach, all the injuries were classified on the basis of their consequences: fatal injuries, injuries with permanent disability of operators, and temporary inability to work.

Referring to the year 1951 (=100, fig 12 ), the reduction of the number of fatalities was much higher than the reduction in permanent or temporary disability.

In 1998 fatal injuries corresponded to $15.18 \%$ of the value recorded in the year 1951 ; injuries with permanent disability were $27.47 \%$, and injuries with temporary inability to work were $30.00 \%$ on the same basis of comparison.

By comparing the values of the three categories of injuries in 1998 with their maximum

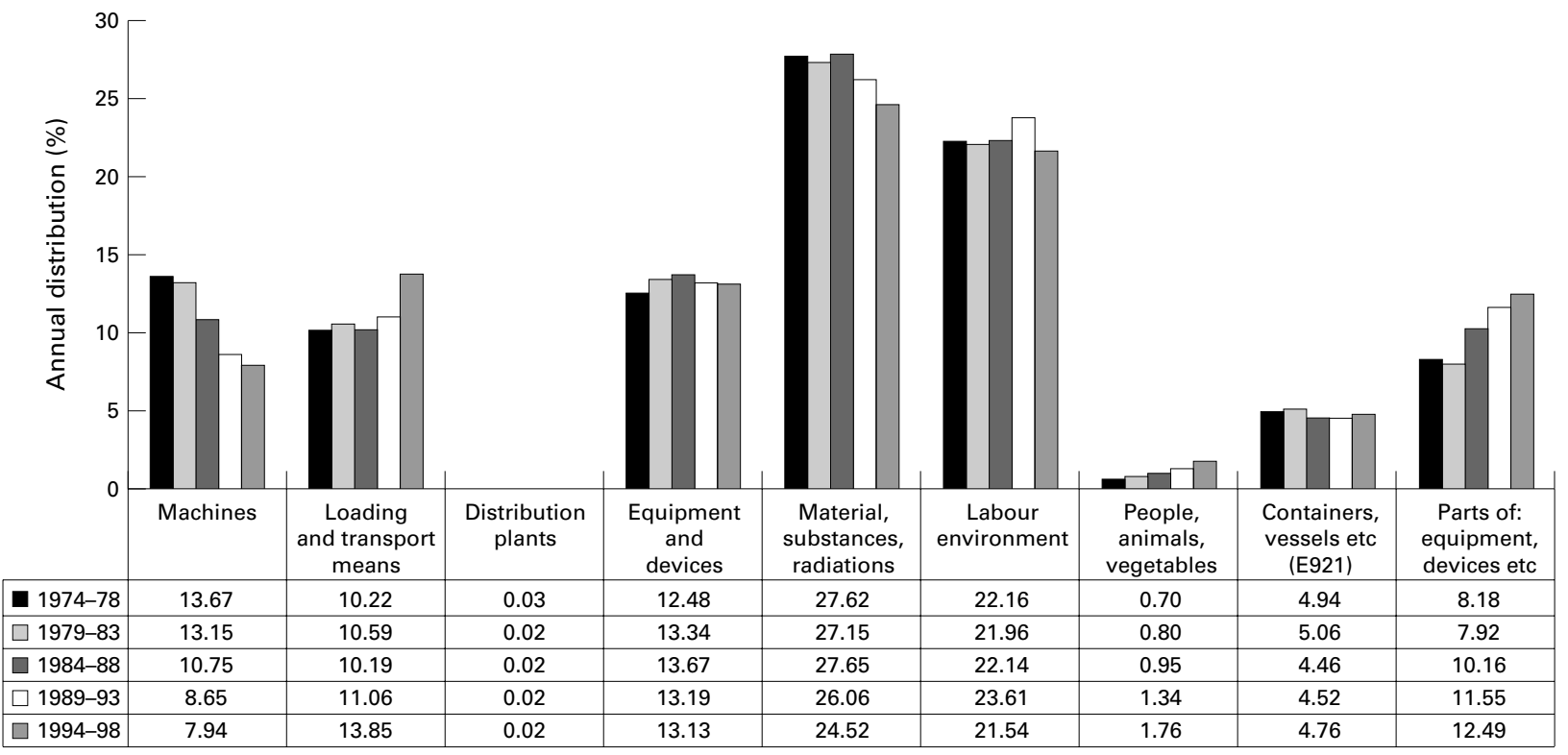

Figure 11 Total injuries from material causes: 5 year averages covering the period 1974-98. 


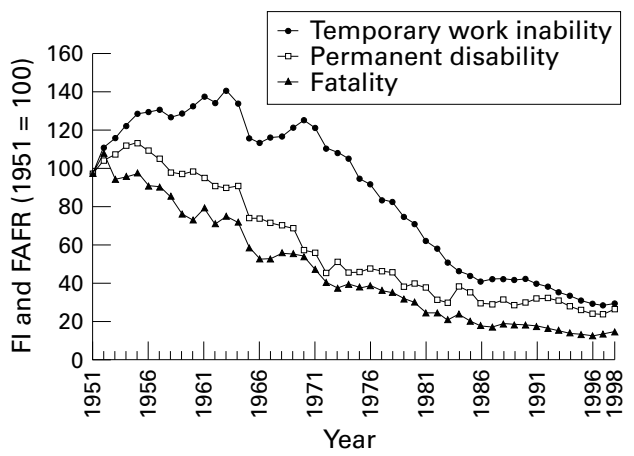

Figure 12 Total frequency indices classified on the basis of severity, over the period 1951-98.

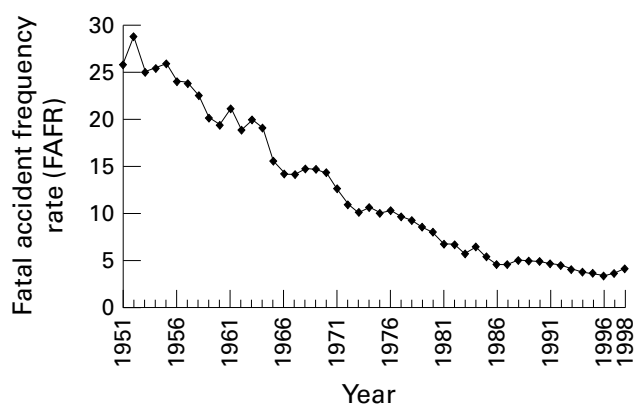

Figure 13 Frequency of fatal accidents over the period 1951-98.

values for the whole period (respectively recorded in 1952, 1955, and 1963), the decline in fatal injures was $86.39 \%$. The reduction in permanent disability was $76.52 \%$, and in the minor injuries it was $79.26 \%$.

These data show that the most effective actions in preventing injuries were directed towards fatalities. This fact is related to the greater importance and different perception of risk given, in the past, to fatal injuries compared with the other levels of injuries. A further contribution to this decline was represented by the general improvement in industrial practice and by the increased standardisation and automation of processes. Because of adoption of preventive actions to reduce risk, the FAFR decreased significantly; however these actions had lower effects on other injuries.

In analyses of 1951-98, the trend for fatal injuries seemed to be more clearly decreasing than that for total injuries (fig 13 and fig 1): this agrees with the results of Bailer et al. ${ }^{21}$ They confirmed that all occupations had significant declines, and for all industries and occupations

Table 1 Estimated annual percentage declines of fatalities according to the linear regression models, for the different industrial sector

\begin{tabular}{lllll}
\hline Industrial sector & $a$ & $b$ & $\begin{array}{l}\text { Coefficient of } \\
\text { determination }\end{array}$ & \% Decline \\
\hline Food or agricultural & 3.980 & -0.066 & 0.823 & 6.36 \\
Chemical & 2.532 & -0.041 & 0.859 & 4.06 \\
Building & 3.988 & -0.032 & 0.907 & 3.14 \\
Energy & 4.140 & -0.065 & 0.911 & 6.33 \\
Wood & 2.111 & -0.019 & 0.550 & 1.87 \\
Metallurgical & 2.546 & -0.008 & 0.260 & 0.81 \\
Mining & 3.890 & -0.041 & 0.909 & 4.00 \\
Textile & 0.571 & -0.007 & 0.129 & 0.72 \\
Transport & 3.621 & -0.031 & 0.890 & 3.03 \\
Overall & 3.385 & -0.045 & 0.970 & 4.42 \\
\hline
\end{tabular}

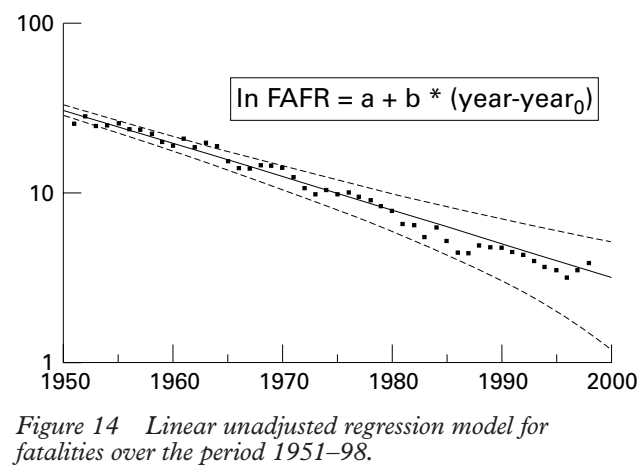

investigated, an annual decline of $3.4 \%$ a year was found.

Table 1 shows the annual percentage variation of fatalities, obtained from the log-link regression models for the different industrial sectors in Italy. The values of the coefficient of determination show the goodness of fit of the fatal injury regression lines for the different sectors: six sectors out of nine had a value for the coefficient above 0.823 . The low value of the coefficient of determination of the textile group is justified by the fact that the FAFR was characterised by very low values and negligible variations in the whole period.

Fatal injury trends for all sectors have decreased exponentially, with an annual decline equal to $4.42 \%$ : the adopted regression model represents well the variation of FAFR in the whole period analysed (coefficient of determination equal to $0.97 ; \mathrm{p}<0.0005)$, as shown in a semilogarithmic diagram (fig 14).

By adopting the bivariate transformed regression model, according to equation 6 , to all industrial sectors, we found an overall adjusted decline in rates of fatal injuries equal to $4.45 \%$ (coefficient of determination equal to $0.98 ; \mathrm{p}<0.0005)$.

From the trend of fatalities in the past few years, we found that the zero injury target does not seem to be achievable, owing to the existence of an inherent minimum number of injuries involving industrial activity. Confirmation of this finding occurred in the textile sector: it had the lowest FAFR but it presented no remarkable variation during the whole period considered in this study. The FAFR of the textile industries was fixed at a mean value of 1.5 and its variations were negligible, with an annual decline of $0.72 \%$.

Our final considerations deal with the trend of FAFR in the different industrial sectors (fig 15). The chemical group was characterised by low values of FAFR, and the reduction in this sector over 48 years corresponds to $73.6 \%$. It must be noted that this variation was restricted to the first 30 years of our study; in the last part of the period the trend was more or less constant (between 1983 and 1997 the reduction was $1.91 \%$ ) with a small increase in the past 5 years.

\section{Discussion}

As already reported, metallurgy industry was the sector with the highest number of workers employed in Italy (about 30\% of working 


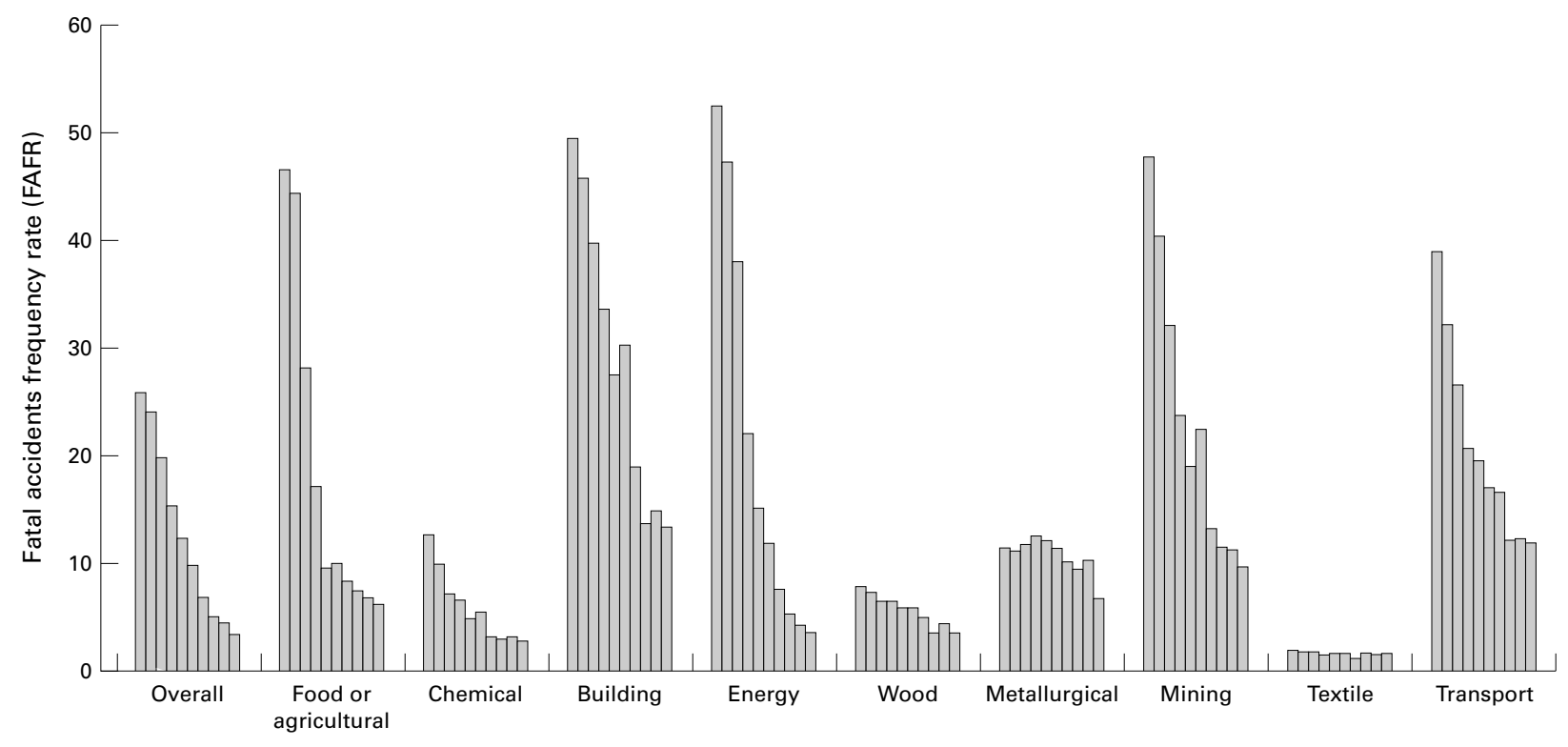

Figure 15 Frequency of fatal accidents: 5 year averages for the different industrial sectors.

hours). We found that the reduction in fatalities in this sector $(40.33 \%)$ was lower than those in other fields. This figure can be related to the fact that, unlike in other sectors, metallurgical industrial practice has not changed remarkably in the past years, especially in small and middle sized firms, which are prominent in Italy.

The wood industry was characterised by a reduction in FAFR of $60.46 \%$; on the other hand, in this industrial sector values of the FI used to be very high, with a particularly high number of injuries causing permanent disability from the use of equipment such as saws. Finally, we found a marked decrease of fatalities in the energy industries $(96.92 \%)$ and in food and agriculture (87.87\%). In these cases the reduction was comparable with that for total injuries, even though the reduction in agricultural production was related also to changes in the classification system used. By contrast, the energy sector was characterised by a sharp improvement in the quality of industrial technology, causing an inherent reduction in safety.

In conclusion, building and transport industries ware characterised by the highest values of FAFR; we found a decline over the full period even though the past 5 years showed an increase, a finding which requires further investigation. The results of this analysis clearly placed the transport and construction groups at a higher fatality risk than manufacturing sectors: transport and construction involve many activities, operations, and practices that have an inherently high risk. ${ }^{22}$ Our analysis agrees well with the findings of Kisner and Fosbroke, ${ }^{23}$ who reported a fatality rate, for construction workers, 3.5 times the overall occupational fatality rate for all industries in the United States.

\section{Conclusions}

This paper shows that many factors affect risk levels in industrial activities. With reference to the Italian situation over a span of half a century, a good correlation between production cycles and injury frequency was found. In agreement with other studies it can be concluded that technological evolution does not in itself prevent industrial injuries. During the period studied the injury rate for all industrial classes showed a decline, with some differences from sector to sector. Several reasons for those differences have been put forward. The analyses of the dynamics of the injuries and of the immediate material causes show that, despite the development of safety techniques in both hardware and software, still more consideration should be paid to the human factor. It was concluded that the overall probability of fatalities is exponentially decreasing by the year and that linear regression models with log transformed rates represent the trend well (coefficient of determination $=0.970$ ). A slight improvement (coefficient of determination $=0.981$ ) of the modelling was verified by adopting a regression model adjusted for the production index. By analysing the rates of fatal accidents in the different sectors, appropriate targets and priorities for increased prevention of injuries can be suggested.

In the light of the evidence produced in this study, the fairest conclusion is that more consideration should be given to the work environment, to the improvement of the man-machine interface, and to human and organisational factors.

1 Pastorino R, Solisio C, De Faveri DM. Riflessioni sui fattori determinanti $i$ livelli di rischio nelle attività industriali. Atti IV Congresso Nazionale della Associazione Italiana degli Igienisti Industriali. Milan, Italy: AIDII, 1982;1:20-9.

2 Butani SJ. Relative risk analysis of injuries in coal mining by age and experience of present company. Fournal of Occupational Accidents 1988;10:209-16.

3 Laflamme 1, Menckel E. Aging and occupational accidents: A review of the literature of the last three decades. Safety Science 1995;21:145-61.

4 Fabiano B, Parentini I, Ferraiolo A, et al. A century of accidents in the Italian industry: relationship with the production cycle. Safety Science 1995;21:65-74.

5 Novek J, Yassi A, Spiegel J. Mechanization, the labor process and injury risk in the Canadian meat packing industry. Int and injury risk in the Canadian

6 Saari J. Accidents and progress of technology in Finnish industry. Fournal of Occupational Accidents 1982;4:133-44. 
7 Blank VLG, Diderichsen F, Andersson R. Technological development and occupational accidents as a conditional relationship: a study over 80 years in the Swedish mining industry. Fournal of Safety Research 1996;27:137-46.

8 Laflamme L. Technological improvement of the production and accidents: an equivocal relationship. Safety Science 1993;16:249-66.

9 Istituto Nazionale Assicurazione Iufertuni sul Lavoro. Notiziario Statistico, Roma, Statistiche per la Prevenzione, Quaderni del Notiziario Statistico, varie annate. Rome, Italy: INAIL, 1974-2000.

10 Angeli F, ed. CENSIS Centre for Social Studies and Policies, Report July 2000. Rome, Italy: CENSIS, 2000.

11 Kletz TA. Accident data: the need for a new look at the sort of data that are collected and analyzed. Safety Science 1993; 16:407-15.

12 The Economist. Economic statistics 1900-83. London: The Economist, 1984.

13 Bailer AJ, Reed LD, Stayner LT. Modelling fatal injury rates using Poisson regression: a case study of workers in using Poisson regression: a case study of workers in 1997; 28:177-86.

14 Kersten E, Ulrich H. Rèsultats d'une étude sur la fréquence des accidents du travail en relation avec la mécanisation et l'automation graduelles des techniques de production.
Zeitscgrift fur Gesamte Hygiene und Ihre Grenzgebieten 1976; 25:370-3.

15 Asogwa SE. The health benefits of mechanization at the Nigerian coal corporation. Accid Anal Prev 1988;20:103-8. 16 World Health Organization. ICD-9 International statistical classification of diseases and related health problems, 9th revision. Geneva, Switzerland: WHO, 1999.

17 Chi CF, Wu ML. Fatal occupational injuries in Taiwan. Safety Science 1997;27:1-17.

18 Shannon HS, Mayr J, Haines T. Overview of the relationship between organizational and workplace factors and injury rates. Safety Science 1997;26:201-17.

19 Blank VLG, Laflamme L, Andersson R. The impact of advances in production technology on industrial injuries. Safety Science 1997;26:219-34.

20 Cuny X, Lejeune $M$. Occupational risks and the value and modelling of a measurement of severity. Safety Science 1999;31:213-29.

21 Bailer AJ, Leslie TS, Stout NA, et al. Trends in rates of occupational fatal injuries in the United States (1983-92). Occup Environ Med 1998;55:485-9.

22 Rabi AZ, Jamous LW, Abu Dhaise BA, et al. Fatal Rabi AZ, Jamous LW, Abu Dhaise BA, et al. Fatal occupational injuries in Jordan during the per
through 1993. Safety Science 1998;28:177-87.

23 Kisner SM, Fosbroke DE. Injuries hazard in the construction industry. F Occup Med 1994;36:136-43.

\section{Correspondence and editorials}

Occupational and Environmental Medicine welcomes correspondence relating to any of the material appearing in the journal. Results from preliminary or small scale studies may also be published in the correspondence column if this seems appropriate. Letters should be not more than 500 words in length and contain a minimum of references. Tables and figures should be kept to an absolute minimum. Letters are accepted on the understanding that they be subject to editorial revision and shortening.

The journal also publishes editorials which are normally specially commissioned. The Editor welcomes suggestions regarding suitable topics; those wishing to submit an editorial, however, should do so only after discussion with the Editor. 